\title{
Vigilância do desenvolvimento psicomotor e sinais de alarme
}

Mónica Pinto*

\section{RESUMO}

Nas últimas décadas tem havido um interesse crescente na patologia do desenvolvimento infantil e na sua detecção e intervenção precoces. Com a evolução da medicina curativa e preventiva nas restantes áreas, o desenvolvimento emerge como um novo desafio a que os médicos têm de fazer frente. Neste artigo, que não pretende ser exaustivo mas apenas um contributo para ajudar a encontrar respostas práticas, revê-se a importância da vigilância do desenvolvimento inserida na vigilância de saúde infantil e os sinais de alarme que devem alertar o médico assistente para que possa tomar uma atitude atempada, permitindo minorar os problemas da criança.

Palavras-chave: Desenvolvimento Infantil; Sinais de Alarme; Prevenção; Vigilância.

\section{INTRODUÇÃO}

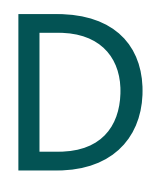

esde os trabalhos de Piaget, que deu maior relevo à perspectiva cognitiva na abordagem da criança, passando por Kohlberg, que introduz o conceito de desenvolvimento moral, e por Vigotsky, que insere três vertentes no desenvolvimento cognitivo - filogénese (evolução humana), história cultural e ontogénese (desenvolvimento individual) - até ao modelo holístico integrado de Magnussen, foi-se gradualmente percebendo a complexidade do desenvolvimento infantil. ${ }^{1,2}$

O interesse pelo desenvolvimento infantil tem crescido nas últimas décadas. Progressivamente, foi aumentando a noção da multiplicidade de factores que podem interferir no desenvolvimento da criança e foi-se adquirindo uma maior capacidade de discernir estes diferentes aspectos e patologias.

Da noção básica de que havia um «atraso do desenvolvimento psicomotor» ou «atraso na fala», foi-se progredindo para um melhor conhecimento das diferentes áreas: a motricidade global (movimentos amplos dos membros), a motricidade fina (coordenação óculo-manual), os sentidos (visão, audição, olfacto, paladar e tacto), a linguagem (compreensão e expressão), a cognição não verbal (realização de construções, encaixes, etc.), o raciocínio prático (noções abstractas), o

Pediatra do Desenvolvimento, Centro de Desenvolvimento do Hospital D. Estefânia Clínica GERAÇÕES.

Centro DIFERENÇAS/APPT21. comportamento, as emoções, as competências sociais e a autonomia.

Sabemos que a criança é um produto de vários factores: da evolução adaptativa da sua espécie, dos genes que herdou dos seus pais, do ambiente físico social e cultural em que vive e das experiências de interacção que vivencía nesse ambiente. O papel do médico assistente é, pois, fundamental na vigilância dos diferentes aspectos do desenvolvimento, na detecção precoce dos desvios da normalidade e na orientação atempada para uma intervenção eficaz.

O conhecimento das diferentes etapas do desenvolvimento, a sua antecipação e o aconselhamento dos pais sobre as actividades que podem ajudar a promover a aquisição das competências, podem evitar alguns dos problemas relacionados com factores ambientais e erros ou lacunas na estimulação da criança. Assim, mais do que apenas detectar os desvios patológicos da normalidade, é importante saber detectar também os desvios fisiológicos e passíveis de correcção através de medidas simples. Pode fazer a diferença incentivar os pais a brincar com o seu filho de uma forma mais dirigida, ensinando-os a dirigir os seus estímulos e a saber que jogos usar.

Por outro lado, o reconhecimento dos desvios patológicos é também importante para que as crianças sejam sinalizadas mais cedo. Uma avaliação do desenvolvimento mais completa e especializada e iniciar intervenção o mais precocemente possível, tentando apro- 
veitar a plasticidade cerebral para recuperar algumas competências e para evitar o acumular de dificuldades.

Mary Sheridan foi uma das pioneiras na noção da necessidade de vigilância e detecção precoce dos problemas de desenvolvimento, então muito relacionados com aspectos psicomotores e linguísticos. O seu trabalho e as suas escalas de vigilância são, provavelmente, as mais usadas em todo o mundo e delas derivam todos os trabalhos que têm sido feitos nesta área. ${ }^{3}$

Brazelton, com a escala NBAS (Neonatal Behavioral Assessment Scale $)^{4}$ e Amiel Tison, ${ }^{5,6}$ fizeram focalizar a atenção no recém-nascido. Desde então têm sido também acrescentados aspectos mais ligados com a comunicação, empatia, interacção, emoção e comportamento, não presentes nas escalas iniciais e que vão acrescentando complexidade a esta vigilância infantil.

Várias escalas e guidelines têm sido desenvolvidas estando algumas, como as da Academia Americana de Pediatria, ${ }^{7}$ disponíveis na internet. Estas guidelines, embora com um esquema de vigilância ligeiramente diferente do nosso (incluem uma consulta aos 7 meses) são mais completas, uma vez que abordam aspectos comportamentais e emocionais que não eram contempladas nas escalas de Mary Sheridan. Foram também desenvolvidos testes de rastreio usando material específico mas de aplicação rápida e adequados à consulta de saúde infantil, como o teste de Denver ${ }^{8}$ (que pode ser usado por Pediatras e pelos Médicos de Família), e testes para detecção de patologias mais específicas, como é o caso do M-CHAT (Modified Checklist for Autism in Toddlers), ${ }^{9}$ que deve ser usado especificamente nas consultas dos 18 e dos 24 meses, pelo médico assistente da criança.

Cada médico poderá usar uma grelha ou um teste mais estruturado ou desenvolver a sua grelha, consoante o instrumento que lhe parecer mais perceptível e prático, desde que mantenha a vigilância das etapas e consiga detectar as situações de risco.

De seguida apresentam-se de forma prática as etapas normais do desenvolvimento e os sinais de alarme a vigiar, com base na escala da Mary Sheridan mas adicionando alguns itens resultantes da crescente complexidade desta área e da experiência obtida na prática. Desta forma, as etapas e sinais de alarme que são apresentados resultam da compilação de várias escalas, abordando aquisições não apenas psicomotoras, mas também emocionais, comportamentais e de autonomia que foram agregadas com base na experiência pessoal da autora e da sua equipa de trabalho, e que permitem vigiar os aspectos relevantes sem obrigar a recorrer a uma multiplicidade de escalas específicas.

\section{PRIMEIRO EXAME DO RECÉM-NASCIDO}

No primeiro exame do recém-nascido (RN) deve ter-se em atenção a sua postura e tónus, se reage ao som e se fixa o olho de boi ou a face humana e a presença dos reflexos primitivos ou inatos (como a sucção, preensão palmar e plantar, reflexo tónico assimétrico do pescoço, reflexo de endireitamento do tronco, marcha automática e o Moro).

De notar que para valorizar os achados no exame devemos ter em conta em que estádio se encontra o RN (a dormir, sonolento, acordado, vigil e activo, irritado e a chorar). Idealmente, deve ser observado em vigília e é importante perceber como regula a transição entre os estádios (por ex. se passa abruptamente do sono para a irritabilidade).

Deve ainda avaliar-se a tensão da fontanela e a simetria dos movimentos e reflexos osteotendinosos.

\section{ALARME}

- O RN demasiado rígido, irritável, com espasticidade global ou localizada com reflexos osteotendinosos aumentados, pode ter uma lesão cerebral periparto.

- A presença de assimetrias pode fazer-nos pensar em lesões localizadas e a fontanela procidente com olhar em sol poente sinalizar hipertensão intracraniana.

- O RN demasiado hipotónico, que não recupera a sua posição em semi-flexão dos membros, que não tem bons reflexos primitivos, ou seja, presentes e simétricos, e que tem reflexos osteotendinosos fracos ou abolidos e dificuldade na regulação do sono pode ter patologia metabólica ou neuromotora e deve ser referenciado.

- Não esquecer, no entanto, que se o RN está a dormir, se acabou de comer ou se é prematuro pode ter esta hipotonia sem patologia subjacente. Assim como se estiver com fome pode mostrar-se tão irritado que se torna hipertónico. No entanto deve ser reavaliado em breve e ponderada a necessidade de referenciação. As escalas de Amiel-Tison ou de Brazelton podem ser úteis na avaliação do RN. 


\section{4-6 SEMANAS}

\section{Motricidade global}

- Em decúbito ventral, levanta a cabeça de forma intermitente, no entanto se traccionado pelas mãos ainda não tem controlo cefálico.

- Em decúbito dorsal apresenta reflexo tónico assimétrico do pescoço.

- Mantém reflexos primitivos (marcha automática, preensão palmar, etc.).

- Sentado, mantém o dorso em arco.

- Em suspensão ventral mantém cabeça erecta e membros semi-flectidos.

\section{Motricidade fina/visão}

- As mãos ainda estão muito fechadas.

- A visão é imperfeita, vendo apenas contrastes fortes e formas redondas (bola vermelha, olho de boi, face da mãe) que segue na horizontal se colocado a $20 \mathrm{~cm}$ da face e num ângulo de $90^{\circ}$.

- Pode apresentar estrabismo, porque o controlo dos músculos oculares é ainda pouco eficaz.

\section{Linguagem/audição}

- Reage ao som da roca ou voz a $15 \mathrm{~cm}$ do ouvido, podendo parar ou olhar para a fonte do som. Pode ainda não ter capacidade motora para virar a cabeça para a fonte sonora.

\section{Autonomia/socialização/comportamento}

- Fixa a face da mãe quando esta o alimenta.

- Sorriso social às seis semanas.

- Chora com desconforto e emite sons guturais em situações de prazer.

- Já regula bem os estádios de sono/vigília e chora mas é consolável.

\section{ALARME}

- Ausência de tentativa de controlo cefálico.

- Hiper ou hipotonia (que podem ser sinais das patologias acima descritas no RN).

- Não segue a face humana ou o olho de boi ou apresenta movimentos erráticos dos olhos.

- Não vira os olhos para o som (mesmo da voz humana), parecendo não reagir ao mesmo.

- Dificuldade em se manter alerta com transições abruptas entre o sono e a irritabilidade, revelando má regulação dos estádios.

\section{MESES}

\section{Motricidade global}

- Em decúbito ventral eleva a cabeça e o tronco, com apoio nos antebraços.

- Em decúbito dorsal estica as pernas e dá pontapés de forma ritmada e simétrica.

- Quando apoia os pés flecte as pernas não fazendo força para ficar de pé.

- Quando traccionado pelas mãos, mantém a cabeça erecta e rectifica a metade superior do dorso.

\section{Motricidade fina/visão}

- Abre e fecha as mãos.

- Brinca com elas e levando-as à linha média (à boca).

- Tenta agitar objectos com a mão. Quando colocada na mão, segura a roca e leva-a para a face e agita-a.

- Olha com interesse para faces.

- Reconhece faces e objectos familiares a pouca distância.

- A visão continua imperfeita mas segue na horizontal e na vertical o movimento da bola vermelha.

- Ainda pode ter estrabismo, sobretudo quando se aproxima o objecto, com pestanejo de defesa, uma vez que a convergência não está bem consolidada.

\section{Linguagem/audição}

- Reage ao som, localizando a fonte sonora e virando a cabeça.

- Sorri reconhecendo a voz da mãe.

- Emite monossílabos mais variados.

- Começa a imitar alguns sons.

- Gosta do diálogo em interacção com pequenos sons de resposta. É importante a mãe incentivar este tipo de interacção e dar tempo para obter uma resposta do bebé, de forma a que haja, de facto, uma comunicação entre ambos.

\section{Autonomia/socialização/comportamento}

- Sorriso social.

- Gosta de brincar com outras pessoas e pode chorar quando a brincadeira acaba.

- Mais expressivo, comunica mais com a face e o corpo.

- Faz movimentos de antecipação quando o vão pegar.

- Imita alguns movimentos e expressões faciais. 
ALARME

- Não fixa nem segue objectos, nem mesmo a face humana.

- Não vira os olhos para o som (sobretudo com a voz humana).

- Não sorri.

- Não tem controlo cefálico.

- Mãos sempre fechadas, não as abrindo mesmo se estimulado o dorso da mão.

- Membros rígidos em repouso, espástico.

- Sobressalto ao menor ruído.

- Chora e grita quando se toca.

- Pobreza de movimentos.

- Mais uma vez estes sinais de alarme ajudam a detectar patologia periparto, metabólica ou défices sensoriais graves.

\section{MESES}

Motricidade global

- Em decúbito ventral, faz apoio nas mãos.

- Em decúbito dorsal eleva a cabeça e os membros inferiores; descobre os pés podendo agarrá-los e levar à boca já que nesta fase há uma hipotonia transitória com grande flexibilidade de movimentos.

- Rola e vira-se, pode já conseguir deslocar-se tipo ponteiros do relógio quando em decúbito ventral.

- Quando traccionado pelas mãos, faz força para sentar. Pode ficar sentado sem apoio, mas ainda não tem reacções de protecção lateral, pelo que pode cair.

- De pé faz apoio.

\section{Motricidade fina/visão}

- Faz preensão palmar, alcançando o objecto voluntariamente, transfere de uma mão para a outra e pode já segurar dois brinquedos.

- Leva objectos à boca como forma de exploração (oral).

- Não tem noção de permanência do objecto pelo que esquece o que sai do seu campo visual, não procurando o brinquedo que cai.

- A visão é agora nítida e a convergência melhor, sendo o estrabismo raro ou inconstante e apenas em situações extremas do olhar.

- Completa o desenvolvimento da visão cromática.

- Amadurece visão à distância e capacidade de seguir objectos.

\section{Linguagem/audição}

- Reage com localização da fonte sonora a $45 \mathrm{~cm}$ do ouvido.

- Vocaliza com mono e dissílabos variados, gostando de conversar e de interagir.

- Responde ao som fazendo sons.

- Reage ao seu nome e começa a perceber o «não».

\section{Autonomia/socialização/comportamento}

- Muito activo, atento e curioso, gostando do jogo social e manifestando alegria com frequência.

- Interesse por imagens no espelho.

- Reage às expressões faciais dos outros.

- Dá os braços para o agarrarem ao colo.

- Inicia o treino da colher (papa e sopa).

\section{ALARME}

- Ausência de controlo cefálico.

- Membros inferiores rígidos, com passagem directa à posição de pé quando se tenta sentar, revelando espasticidade.

- Não olha nem pega em objectos, o que pode ser por défice sensorial, por falta de interesse na exploração ou por incapacidade motora para o fazer.

- Assimetrias (usar só uma mão, por exemplo, pode ser sinal de patologia localizada cerebral - acidente vascular cerebral ou atrofia cortical localizada pós asfixia).

- Não reage aos sons por surdez ou desinteresse.

- Não vocaliza, silencioso ou muito monocórdico.

- Desinteresse do ambiente, não estabelece contacto, apático.

- Irritabilidade, estremece sempre que é tocado.

- Estrabismo manifesto e constante.

- Persistência de reflexos primitivos.

\section{MESES}

\section{Motricidade global}

- Fica sentado, sem apoios, por 10-15 min, uma vez que tem reacções de protecção lateral e melhor equilíbrio.

- Põe-se de pé com apoio mas não se baixa.

- Desloca-se rastejando ou tentando gatinhar.

Motricidade fina/visão

- Preensão e manipulação. 
- Leva tudo à boca para exploração oral.

- Aponta com indicador, gosta de premir botões e explorar buracos.

- Faz pinça fina (apanha migalhas ou um fio da mesa).

- Atira objectos deliberadamente para o chão para ter noção do limite do seu corpo e da profundidade do espaço.

- Procura objecto que caiu, pois já tem noção de permanência do objecto.

\section{Linguagem/audição}

- Reage de forma rápida a sons perto e longe.

- Localiza sons acima e abaixo do nível do ouvido.

- Palra com polissílabos (mamama, tatata...) e imita mais sons do adulto, sendo estes polissílabos um sinal importante de bom prognóstico da evolução da fala.

\section{Autonomia/socialização/comportamento}

- Leva a comida à boca (bolacha, pão, massa) e apanha migalhas.

- Mastiga e, caso ainda não o faça por falta de estimulação, éfundamental reforçar a importância de incentivar a mastigação einiciar a manipulação da colher e do copo.

- Distingue os familiares dos estranhos (reacção ao estranho com choro) e manifesta afecto dando «miminhos».

\section{ALARME}

- Não se senta.

- Permanece imóvel e não tenta mudar de posição.

- Assimetrias, posturais ou de movimentos.

- Estrabismo, mesmo que inconstante.

- Sem preensão palmar e não explora objectos oralmente.

- Não reage aos sons.

- Vocaliza monotonamente ou deixa de vocalizar

- Apático e sem reacção aos familiares.

- Engasga-se com facilidade.

\section{MESES}

Motricidade global

- Passa de decúbito dorsal a sentado.

- Tem bom equilíbrio sentado.

- Gatinha ou desloca-se rastejando ou mudando de posição.

- Põe-se de pé e baixa-se com ajuda das mãos, anda com apoio.

\section{Motricidade fina/visão}

- Explora os brinquedos de várias formas.

- Procura o objecto escondido (debaixo de um pano ou embrulhado) e abre a caixa à procura do conteúdo.

- Tem interesse visual para perto e para longe (já vê o avião ou o passarinho).

- Bate um cubo no outro em imitação. Usa objectos de forma funcional (copo, telefone, escova cabelo, etc.).

\section{Linguagem/audição}

- Reage rápido a sons suaves.

- Volta-se quando o chamam pelo nome.

- Compreende ordens simples («dá») e expressa o «não» com a cabeça.

- Palra muito com sons parecidos com os do adulto variando o tom (jargão) e de forma expressiva. Tenta imitar palavras.

- Pode dizer la4 palavras ou sons, que aplica com intenção.

- Identifica, olhando, imagens quando nomeadas pelo adulto.

\section{Autonomia/socialização/comportamento}

- Bebe pelo copo com ajuda.

- Segura a colher, mas não a usa sozinho. Come com a mão.

- Ajuda a vestir levantando os braços.

- Diz adeus, bate palminhas e imita gestos do adulto.

- Sorri ao espelho.

- Muito dependente do adulto e chora na separação. Tímido ou ansioso com estranhos.

- Demonstra afecto, gosta da interacção, do jogo social e da imitação do adulto.

- Completa a sua «gestação extra-uterina» ficando equiparado às crias precociais quando nascem anda, come, comunica - podendo a partir de agora transitar para o seu quarto e iniciar o processo de autonomia.

\section{ALARME}

- Não aguenta o peso nas pernas, por hipotonia; não se senta.

- Permanece imóvel e não tenta mudar de posição.

- Assimetrias; estrabismo.

- Não pega nos brinquedos ou fá-lo só com uma mão.

- Não faz pinça fina. 
- Não responde à voz, não emite polissílabos, fica muito silencioso.

- Não brinca, nem estabelece contacto, não reage ao nome, não segue o apontar dos pais, podendo estes ser sinais de alerta para possibilidade de perturbação da empatia, ou seja, perturbação do espectro do autismo.

- Não mastiga - como já referido, é fundamental fazer um treino activo da mastigação e das competências de autonomia.

\section{MESES}

\section{Motricidade global}

- Começa a dominar a marcha, ainda de base alargada. Pode ainda andar só com apoio, já que a marcha autónoma pode surgir entre os 9 e os 18 meses, sendo mais importante a noção de que a criança se desloca de alguma forma.

\section{Motricidade fina/cognição não verbal}

- Começa a definir a lateralidade dominante, usando mais uma mão, mas utilizando a outra como mão de apoio.

- Segura o lápis como se fosse escrever.

- Empilha dois cubos, rola a bola.

- Põe e tira objectos de recipientes.

\section{Linguagem/raciocínio prático}

- Tem 4-5 palavras mas compreende muito mais e identifica objectos a pedido.

- Olha para o que os pais apontam, iniciando uma atenção conjunta e triangulando o olhar com os pais e objectos.

- Aponta para pedir (proto-imperativo) e depois para mostrar (proto-declarativo), como forma de interacção social.

- Tenta cantar, gosta de música e de ver o livro de imagens.

\section{Autonomia/socialização/comportamento}

- Bebe pelo copo e usa a colher.

- Procura a independência e tem noção de território e de posse. É a altura em que foge aos pais e começa a fazer birras.

- Reage à frustração com atitudes primitivas: grita, arranha, morde.

\section{ALARME}

- Ausência de tentativa de se deslocar ou de explorar o ambiente.

- Exploração dos objectos ainda prioritariamente oral.

- Não faz sons variados e polissílabos, não tenta imitar o som do adulto.

- Não faz pinça fina e não usa funcionalmente os objectos.

- Não aponta ou tenta usar o gesto como suporte da comunicação.

- Não cumpre ordens simples.

\section{MESES}

\section{Motricidade global}

- Anda bem, recua, baixa-se e apanha um brinquedo do chão e dá uma corrida pequena.

- Sobe escadas com apoio.

\section{Motricidade fina/cognição não verbal}

- Tem a lateralidade mais definida, faz rabiscos no papel, empilha três cubos.

- Olha para o livro e volta páginas, com mais interesse no conteúdo.

- Faz puzzle de três peças com formas simples, com noção de forma e cor.

\section{Linguagem/raciocínio prático}

- Usa 6-26 palavras reconhecíveis e compreende muito mais.

- Mostra três partes do corpo e mostra os sapatos a pedido.

- Identifica objectos de uso corrente e nomeia alguns (bola, carro).

- Usa o gesto para comunicar, aponta, mostra e partilha.

\section{Autonomia/socialização}

- Bebe pelo copo sem entornar, segurando-o com ambas as mãos.

- Usa a colher entornando pouco.

- Descalça sapatos e peúgas.

- Não gosta que lhe peguem, demonstrando independência crescente, mas quer muita atenção. Alguns comportamentos de desafio.

- Ansiedade de separação, que tem um pico por volta dos 18 meses e depois abranda de novo. 
- Imita actividades domésticas, inicia o jogo simbólico.

- Imita o comportamento dos outros.

- Mais noção do seu «eu» e mais excitado com a companhia de crianças, iniciando a socialização.

\section{ALARME}

- Não se põe de pé, anda em pontas; não anda; assimetrias.

- Não faz pinça fina, atira objectos ou leva-os sistematicamente à boca, não apresentando uso funcional.

- Ausência de resposta à voz, não vocaliza espontaneamente, não tem a palavras perceptíveis.

- Não se interessa pelo que o rodeia, não estabelece contacto e não apresenta intencionalidade comunicativa.

- Não cumpre ordens.

\section{ANOS}

\section{Motricidade global}

- Corre bem, chuta a bola, salta a pés juntos, sobe e desce degraus.

\section{Motricidade fina/cognição não verbal}

- Lateralidade mais definida, usa mais uma mão.

- Constrói torres de seis cubos.

- Imita rabisco circular.

- Coordena as duas mãos, deitando água de um para outro recipiente.

- Vê o livro, passando página a página.

- Tem noção de cores e formas e sabe seleccionar por grupos iguais.

- Desenrosca a tampa da garrafa.

Linguagem/raciocínio prático

- Diz o primeiro nome.

- Faz monólogos enquanto brinca.

- Diz holofrases (já tá e dá cá) e junta palavras (mãe rua, quero papa).

- Identifica muitos objectos e pessoas e nomeia alguns objectos.

- Segue ordens simples.

- Repete palavras que ouviu.

\section{Autonomia/socialização/comportamento}

- Inicia treino dos esfíncteres diurno.

- Pede brinquedos; ainda faz jogo paralelo mas gosta de interagir.
- Pede alimentos à mesa, come bem com a colher e bebe pelo copo sem entornar.

- Ajuda a vestir, põe o chapéu e calça sapatos e identifica várias partes do corpo.

- Imita comportamento dos adultos e outras crianças. Tem jogo imitativo - em que imita acções dos outros - e jogo simbólico - em que usa objectos fingindo ser algo diferente ou recria personagens.

- Gosta de brincar com outros mas é muito possessivo e com independência crescente.

- Começa a testar limites e regras parentais, é desafiante e faz birras.

- É importante perceber a vinculação, a estruturação parental e as rotinas que estão implementadas em relação à alimentação, sono, higiene, controlo de birras, para dar estratégias aos pais e evitar agravamento dos problemas no futuro.

\section{ALARME}

- Não anda ou anda sistematicamente em pontas, o que pode ser um sinal de hipertonia distal dos membros inferiores ou alertar para aspectos comportamentais (por ser uma estereotipia).

- Deita objectos fora e não constrói nada.

- Não parece compreender o que lhe dizem.

- Não tem palavras inteligíveis.

- Não procura imitar, não se interessa pelo meio e pelas pessoas e não tenta interagir.

- Não aponta, não pede, não mostra.

- Birras desajustadas em frequência e intensidade ou sem motivos aparentes.

\section{ANOS}

\section{Motricidade global}

- Tem equilíbrio momentâneo num pé.

- Salta a pés juntos e sobe degraus alternando o pé.

- Anda em bicos de pés de forma voluntária.

- Corre, chuta a bola e pedala o triciclo.

Motricidade fina/cognição não verbal

- Faz torre de oito cubos, imita a ponte de três cubos.

- Enfia contas, enrosca e tenta cortar com tesoura.

- Imita a cruz e copia o círculo (ainda incompleto).

- Selecciona por cores e faz puzzles tendo noção de forma e de tamanho.

- É importante que conclua as tarefas, embora o tempo de concentração seja muito curto (5-10 min). 
Linguagem/raciocínio prático

- Sabe o nome e apelido e o sexo.

- Pergunta, canta, define objectos pelo uso.

- Usa frases de 3 a 5 palavras, com advérbios e adjectivos.

- Vocabulário extenso mas que pode ser incompreensível para estranhos e ter defeitos de articulação e imaturidades na fala.

- Conhece o dinheiro, tem noção de maior, compara tamanhos e repete três dígitos (memória verbal imediata).

\section{Autonomia/socialização/comportamento}

- Usa a casa de banho sozinho, mas pode não controlar a micção durante a noite.

- Come com colher e garfo.

- Desabotoa botões (ainda não abotoa).

- Tem jogo imaginativo e partilha a brincadeira com os outros; pode ter um amigo imaginário ou brincadeiras com fantasia.

- Adquire noção de ironia, faz «palhaçadas» e é muito social, embora possa variar com o temperamento de cada criança.

- As birras são mais intencionais, surgem os terrores nocturnos, os medos e fobias porque tem mais noção do ambiente e dos perigos.

- Muito egocêntrico e incapaz de adiar a recompensa ou de esperar a sua vez.

- Já consegue estar separado dos pais sem grande ansiedade e tem alguma dificuldade em lidar com alterações na rotina.

\section{ALARME}

- Anda sistematicamente em pontas.

- Mantém flapping dos braços quando excitado. Este comportamento pode ser normal até esta idade, desde que seja isolado e não associado a outras estereotipias, mas deve desaparecer a partir dos três anos.

- Não parece compreender o que lhe dizem, não junta duas palavras.

- Não usa funcionalmente os objectos e não tenta fazer algo construtivo ou criativo.

- Não tenta interagir com os outros, não socializa, não mostra, não partilha, não pede.

- Não usa o gesto como suporte da comunicação no caso de dificuldades na expressão verbal.

\section{ANOS}

Motricidade global

- Salta num pé, corre, pedala e anda em cima de um muro, com maior capacidade de equilíbrio.

- Sobe e desce escadas com alternância dos pés.

\section{Motricidade fina/cognição não verbal}

- Faz construções e puzzles mais complexos (escada de seis cubos).

- Copia a cruz e o quadrado.

- Desenha a figura humana (girino).

- Faz dobragens em imitação, corta com tesoura.

- Nomeia quatro a seis cores.

Linguagem/raciocínio prático

- Linguagem compreensível mesmo por estranhos, contando histórias, com mais vocabulário e usando pronomes.

- Pode ter algumas substituições e trocas fonéticas.

- Sabe onde vive e tem noção dos espaços dentro de espaços (que Lisboa fica em Portugal, por exº.).

- Compara tamanhos, comprimentos e pesos.

- Conta até quatro, com noção de quantidade.

- Memória de repetição de quatro dígitos.

- Sabe a idade.

\section{Autonomia/socialização}

- Veste e despe-se com ajuda. Come sozinho com garfo e colher.

- Ajuda nas tarefas domésticas.

- Interessado em novas experiências e curioso.

- Brinca com outros e gosta do jogo simbólico e de fantasia. Mais independente e começa a saber resolver conflitos.

- Tem noção dos seus pensamentos e sentimentos, alguns medos dos «monstros» e dificuldade em separar a fantasia da realidade.

- Aumento gradual da concentração para 10-15 min e aprende a esperar a sua vez.

\section{ANOS}

Motricidade global

- Corre e chuta a bola, sobe e desce escadas e tem grande agilidade e autonomia.

- Atira bola ao ar e apanha. 


\section{Motricidade fina/cognição não verbal}

- Desenha com mais detalhes a figura humana, faz uma casa e formas variadas, desenha o triângulo.

- Recorta bem com tesoura.

- Faz construções mais elaboradas e tem noção de padrões e sequências.

\section{Linguagem/raciocínio prático}

- Discurso fluente podendo ter pequenas incorrecções articulatórias ou sigmatismo que devem tentar ser corrigidos antes de iniciar a escola (nesta fase já há boa colaboração da criança).

- Grande aumento de vocabulário, com definição de opostos, materiais, noções temporais e de velocidade.

- Usa frases de 5 palavras e com tempos verbais, embora por vezes com algumas incorrecções gramaticais.

- Conta até 15 e conhece as moedas.

\section{Autonomia/socialização}

- Lava-se, veste-se e despe-se sem ajuda. Come com faca e garfo.

- É autónomo na casa de banho.

- Escolhe os amigos, gosta de lhes agradar e por vezes tenta imitá-los.

- Gosta de dançar, cantar e fazer teatro e já é capaz de ficar sozinho com os amigos ou em casa de vizinhos.

- Distingue a fantasia da realidade.

- Compreende as regras do jogo.

- Concentração aumenta (15-20 min).

\section{ANOS}

\section{Motricidade global}

- Bate a bola e apanha, atira ao ar e apanha.

- Saltita e salta bem ao «pé coxinho».

\section{Motricidade fina/cognição não verbal}

- Desenha a figura humana e a casa com pormenor, escreve letras e alguns números, escreve o seu nome.

- No caso de ainda não ter lateralidade bem definida (pode só se completar por volta dos sete anos) pode cometer erros visuoespaciais e desenhar letras em espelho e ainda não ter a noção das regras de escrita (sequência da esquerda para a direita, que as letras devem ficar todas juntas e as palavras separadas por espaços, etc.), o que deve ser corrigido e ensinado activamente. Não são indicadores de dislexia, nem de necessidade de correcção visual.

- Faz encaixes complexos e construções criativas e replica formas sem modelo.

\section{Linguagem/raciocínio prático}

- Fala bem, com vocabulário rico, palavras descritivas e partículas de ligação; boa sintaxe. Gosta de ajudar e sabe fazer tarefas de forma autónoma.

- Faz adições simples contando pelos dedos e tem memória de cinco dígitos.

- Tem um amigo preferido, interesses mais específicos e atenção dirigida (30-50 min), estando apto a iniciar a escola.

\section{ALARME (dos 4 aos 6 anos)}

- Hiperactivo e agitado, ou distraído e com dificuldades de concentração, que não vai melhorando ao longo deste período podem ser indicadores de Perturbação de Hiperactividade e Défice de Atenção, se não houver um aumento progressivo do tempo de atenção.

- Comportamento muito difícil, opositivo e desafiante que não é controlável pelos pais justifica uma referenciação.

- Problemas de interacção social, associados ou não a comportamentos repetitivos e estereotipados e dificuldades na comunicação e empatia, que podem ser sinal de perturbação do espectro do autismo ou Síndrome de Asperger.

- Linguagem incompreensível aos quatro anos, não conseguindo descrever uma figura, ou com substituições fonéticas e erros articulatórios presentes aos cinco ou seis anos, necessitam avaliação e intervenção.

- A criança com dificuldade na aprendizagem das letras ou que na escola (aos sete anos) não aprende a ler pode ter uma dislexia e deverá também ser referenciada.

- Suspeita de défices auditivos e visuais mais ligeiros que devem sempre ser vigiados e detectados, sobretudo em crianças com problemas do desenvolvimento. Se por um lado é feito o rastreio de otoemissões ao nascer e nas diferentes etapas se foi avaliando a audição e visão, no caso de haver suspeitas de 
défices devem sempre ser avaliados e orientados por um oftalmologista ou otorrinolaringologista ou pedido audiograma e timpanograma e um rastreio da visão.

\section{O QUE PODEMOS FAZER E O QUE NÃO DEVEMOS FAZER}

Todos os profissionais que seguem crianças e fazem a sua vigilância devem ter atenção às variações dentro da normalidade. É, por isso, fundamental que tenham a noção do normal, das situações em que podemos recomendar reforço da estimulação e manter vigilância e das situações em que a acção deve ser mais premente.

É necessário ter presentes as etapas acima referidas e os sinais de alerta e, em cada consulta de saúde infantil, não esquecer de rever estas aquisições. Podem ser usados testes ou grelhas de rastreio, mas o importante é ter presente que a acção atempada pode fazer diferença.

É também importante valorizar as queixas/preocupações dos pais, que são, frequentemente, fundamentadas. Ainda que por vezes o seu foco de preocupação não seja de facto no que está alterado é, geralmente, um sinal de que algo não está bem.

Devemos actualizar continuamente os nossos conhecimentos e ter a mente aberta à evolução desta área da Pediatria, procurando não ser contaminados por antigos dogmas, como « a criança vai falar quando for para a creche» ou que «não fala porque tem o freio curto» ou «porque a avó falava pouco com ela». Devemos referenciar de forma atempada para confirmação das suspeitas, numa consulta de desenvolvimento ou investigar patologia sensorial ou neurológica.

Não devem ser feitos prognósticos sobre a inteligência futura de uma criança, porque o seu potencial e a sua plasticidade dependem de muitos factores que são imprevisíveis e surpreendentes, como nos refere Illingsworth. ${ }^{10}$

Nem sempre podemos saber se uma alteração é ou não transitória e, muitas vezes, só detectamos pequenas alterações tardiamente, pelo que é muito importante a forma de abordar os pais, valorizando-os, ouvindo-os, dando-lhes sempre apoio e nunca os deixando perder a força e a esperança. Nunca devemos ser muito categóricos nos diagnósticos até confirmação, uma vez que não há uma linha que separe o normal do patoló- gico, mas sim uma franja cinzenta onde muito pode acontecer. E mesmo após uma confirmação diagnóstica, cabe-nos ajudar a abrir portas aos apoios, de forma a que os pais se sintam ajudados e não desistam de investir no futuro da sua criança.

\section{AGRADECIMENTO}

Quero deixar um agradecimento especial ao Dr. Miguel Palha, meu mestre e amigo que me ensinou muito e me fez dar os primeiros passos nesta matéria.

\section{REFERÊNCIAS BIBLIOGRÁFICAS}

1. Matlin MW. Cognitive development throughout the lifespan. In: Cognition. Philadelphia, PA; Wiley; 2005. p. 451-64.

2. Illingworth RS. The development of the infant and young child, normal and abnormal. 9th ed. London: Churchill Livingstone; 1987.

3. Sheridan MD. From birth to five years: children development progress. Hong Kong: The Nfer-Nelson Publishing Company; 1984. p. 1-74.

4. Brazelton T. Neonatal Behavioral Assessment Scale. 2nd ed. Philadelphia, PA: Blackwell; 1984.

5. Amiel-Tison C. Exploração da função cerebral do recém-nascido. Médicine Périnatale; 1989.

6. Amiel-Tison C. Update of the Amiel-Tison neurologic assessment for the term neonate or at 40 weeks corrected age. Pediatr Neurol. 2002 Sep; 27 (3): 196-212.

7. Shelov S, Hannermann RE. Caring for your baby and young child: Birth to age 5. American Academy of Pediatrics; 2004.

8. Frankenburg WK, Dodds JB. The Denver Development Screening Test. J Pediatr 1967 Aug;71 (2): 181-91.

9. Robins DL, Fein D, Barton ML, Green JA. The Modified Checklist for Autism in Toddlers: an initial study investigating the early detection of autism and pervasive developmental disorders. J Autism Dev Disord 2001 Apr; 31 (2): 131-44.

10. Illingworth RS. Pitfalls in developmental diagnosis. Arch Dis Child 1987 Aug; 62 (8): 860-5.

A autora declarou não possuir conflitos de interesses.

\section{ENDEREÇO PARA CORRESPONDÊNCIA}

Mónica Pinto

Av. Fontes Pereira de Melo, $\mathrm{n}^{\circ} 3,10^{\circ}$ Dto.

1050-115 Lisboa

E-mail: monicapinto2010@mail.com 


\section{ABSTRACT}

\section{THE SURVEILLANCE AND WARNING SIGNS OF CHILD'S DEVELOPMENT}

Over the last few decades, there has been a growing interest in pediatric developmental problems, their early diagnosis and intervention. The advances in therapeutics and preventive medicine in other fields opened the way for development to emerge as a new challenge for doctors. This paper will review the importance of developmental surveillance within the pediatric clinical setting and the warning signs that should alert doctors to act timely to prevent or minimize disease progression. Although not exhaustive, this review article intends to give practical solutions to clinicians.

Keywords: Child Development; Signs; Prevention; Surveillance. 